Tersedia online di: http://ejournal-balitbang.kkp.go.id/index.php/JP
e-mail:jurnalpari@gmail.com
JURNAL PARI
volume 5 Nomor 1 Juli 2019
p-ISSN: 2502-0730
e-ISSN : 2549-0133

\title{
PENGELOLAAN ARSIP DINAMIS INAKTIF PADA STASIUN KARANTINA IKAN, PENGENDALIAN MUTU DAN KEAMANAN HASIL PERIKANAN PONTIANAK
}

\author{
Rini Tajuddin dan Heri Susanto \\ Stasiun Karantina Ikan Pengendalian Mutu dan Keamanan Hasil Perikanan Pontianak, Jalan Arteri Supadio \\ Km. 18 Kab. Kubu Raya Kalimantan Barat, Indonesia \\ Diterima tanggal : 27 Mei 2019 Diterima setelah perbaikan : 27 Juni 2019 \\ disetujui terbit : 10 Juli 2019
}

\begin{abstract}
ABSTRAK
Artikel ini membahas mengenai belum optimalnya Pengelolaan Arsip Dinamis Inaktif dilingkup Stasiun Karantina Ikan Pengendalian Mutu dan Keamanan Hasil Perikanan Pontianak dalam hal penyimpanan, pemeliharaan dan keamanan, serta menemukan upaya untuk mengatasi penyusutan atau pemusnahan arsip sesuai dengan memperhatikan atau mengamati pada Jadwal Retensi Arsip (JRA). Mekanisme Pengelolaan Arsip Dinamis Inaktif sudah sesuai dengan mekanisme yang berlaku terutama dalam pemindahan arsip dinamis inaktif dari Unit Pengolah menuju Unit Kearsipan. Fasilitas yang dipergunakan Unit Kearsipan Stasiun Karantina Ikan , Pengendalian Mutu dan Keamanan Hasil Perikanan Pontianak didalam Pengelolaan Arsip Dinamis Inaktif sudah sesuai tetapi masih perlu diperdayagunakan secara maksimal dalam membantu pengelolaan arsip dinamis Inaktif seperti penggunaan pengelolaan arsip dinamis inaktif elektronik yang bisa memudahkan pengolah kearsipan dalam mengelola arsip sehingga dalam penemuan kembali arsip lebih mudah. Penelitian ini menggunakan penelitian kualitatif yakni dengan metode studi kasus sedangkan teknik pengumpulan data yang digunakan yaitu wawancara, observasi dan dokumentasi. Hasil penelitian menunjukkan bahwa pengelolaan arsip dinamis inaktif dilingkup Stasiun Karantina Ikan, Pengendalian Mutu dan Keamanan Hasil Perikanan Pontianak belum sepenuhnya optimal, yaitu (1). Fasilitas Kearsipan seperti ruang penyimpanan arsip, fire alarm system dan alat pemadam kebakaran yang belum memadai, Kurangnya rak arsip inaktif hal ini disebabkan karena belum dilaksanakannya pemusnahan arsip, (2). Kurangnya SDM, (3). Peminjaman arsip, arsip yang dipinjam seringkali terlambat dalam pengembaliannya, hal ini dikarenakan masih kurangnya kesadaran peminjam arsip, dan (4). Kurangnya kesadaran dan tidak ada kesamaan pemahaman dari Unit Pengolah yang satu dengan Unit Pengolah yang lainnya dilingkup Stasiun Karantina Ikan, Pengendalian Mutu dan Keamanan Hasil Perikanan Pontianak terkait pengelolaan arsip dinamis inaktif, dan (5). Pemusnahan arsip belum dilaksanakan dikarenakan proses persetujuan pemusnahan arsip harus melalui proses dan sesuai prosedur.
\end{abstract}

\section{Kata Kunci : Arsip, Data, Management, Sistem}

\begin{abstract}
This article discusses the not yet optimal Inactive Dynamic Archive Management in the Fish Quarantine Station in Pontianak Fisheries Quality and Safety Control in terms of storage, maintenance and security, and finds an effort to overcome depreciation or destruction of records according to observing or observing the Archive Retention Schedule (JRA). The mechanism of active dynamic archive management is in accordance with the applicable mechanism, especially in the transfer of inactive dynamic records from the processing unit to the filing unit. The facilities used by the Archives Unit of the Fish Quarantine Station, Pontianak Fisheries Quality and Safety Control in Active Dynamic Archive Management are appropriate but still need to be fully utilized in helping dynamic Inactive file management such as the use of electronic inactive dynamic archive management that can facilitate archiving processors in managing records so that in the rediscovery of archives it is easier. This study uses qualitative research, namely the case study method while the data collection techniques used are interviews, observation and documentation. The results
\end{abstract}


showed that inactive dynamic archive management in the Fish Quarantine Station, Pontianak Fisheries Product Quality and Safety Control was not fully optimal, namely (1). Archival facilities such as archival storage rooms, fire alarm systems and inadequate fire extinguishers, Lack of inactive archive shelves is due to the non-destruction of records, (2). Lack of HR, (3). Archive lending, borrowed archives are often late in return, this is because there is still a lack of awareness of archival borrowers, and (4). Lack of awareness and no similarity of understanding from one Processing Unit to the other Processing Units covered by the Fish Quarantine Station, Pontianak Fisheries Product Quality and Safety Control regarding the management of inactive dynamic records, and (5). The destruction of the archive has not been carried out because the approval process for the destruction of records must go through a process and according to the procedure.

\section{Keywords : Archives, Date, Management, Systems}

\section{PENDAHULUAN}

Dalam pelaksanaan kegiatan Instansi Pemerintahan yang semakin maju dan berkembang maka semakin banyak pula arsip. Arsip semakin hari semakin meningkat keberadaannya sesuai dengan fungsi dan tugas dari sebuah instansi. Masalah yang muncul dari kondisi ini apabila tidak tertata dengan baik dan sistematis maka menumpuknya arsip secara tidak terkontrol di unit pengolah dari masing-masing organisasi. Penataan arsip cenderung terabaikan, lebih diutamakan menyelesaikan tugas pokok lainnya dari pada tugas menata arsip, namun sebenarnya informasi yang dibutuhkan ada keterkaitan dengan arsip itu sendiri serta dalam penemuan kembali arsip sangat tergantung dengan personil yang membidanginya. Dalam dunia kearsipan ataupun penataan surat-surat memang dikenal istilah sistem. Sistem di sini biasanya dipakai untuk menyatakan model penyimpanan. Prosedur penyimpanan arsip adalah langkah langkah pekerjaan yang sehubungan dengan akan disimpannya arsip.

Undang-Undang Nomor 43 Tahun 2009 menjelaskan bahwa pengertian arsip adalah "rekaman peristiwa atau kegiatan.yang diterima oleh lembaga negara, pemerintah daerah, perusahaan, organisasi politik, lembaga pendidikan, dan perseorangan untuk pelaksanaan.kehidupan bermasyarakat yang berupa berbagai bentuk dan media sosial dengan perkembangan komunikasi dan perkembangan teknologi informasi". Berdasarkan.pengertian arsip di atas diketahui bahwa arsip adalah naskah tertulis yang didalamnya memuat keterangan-keterangan penting. Arsip sangat berperan penting dalam suatu lembaga, yaitu sebagai penyajian informasi maupun pusat ingatan bagi seorang pimpinan untuk dapat merumuskan kebijakan dan membuat keputusan, maka untuk dapat memberikan atau menyajikan informasi yang akurat dan lengkap harus memiliki prosedur tertentu dan sistem yang baik dalam pengelolaan kearsipannya. Proses yang sedemikian tersebut dapat menciptakan arsip apapun jenisnya baik yang tekstual maupun non tekstual. Arsip inilah yang suatu saat diberkaskan berdasarkan transaksi dan kegiatannya sesuai kepentingan unit kerja agar mudah dicari dan ditemukan kembali.

Menurut Zulkifli Amsyah (2003 : 3) arsip adalah setiap catatan (record atau warkat) yang tertulis, tercetak, atau ketikan, dalam bentuk huruf, angka atau gambar, yang mempunyai arti dan tujuan tertentu sebagai bahan komunikasi dan informasi, yang terekam pada kertas (kartu, formulir), kertas film (slide, film-strip, mikro-film), media komputer (pita tape, piringan, rekaman, disket), kertas photo copy, dan lain-lain.

Zulkarnain dan Sumarsono (2015:209) menyatakan, manajemen kearsipan adalah pelaksanaan fungsi-fungsi manajemen dalam rangka mengelola keseluruhan daur hidup arsip (life cycle of a records) yang terdiri dari fase: penciptaan dan penerimaan (creation and receipt); pendistribusian (distribution); penggunaan (use); pemeliharaan (maintenance) dan penyusutan (disposition) suatu arsip. Setiap fase di dalam daur hidup arsip ini merupakan sub asas yang mempengaruhi sub asas yang lain. Jadi dengan kata lain tata kearsipan merupakan suatu proses kegiatan mulai dari penerimaan, pengumpulan, pengaturan, pemeliharaan, dan penyimpanan dokumen menurut sistem tertentu, sehingga saat diperlukan dapat ditemukan dengan cepat dan mudah.

Arsip Dinamis Inaktif yaitu arsip yang penggunaannya tidak langsung sebagai bahan informasi. Arsip inaktif ini disimpan di unit kearsipan dan dikeluarkan dari tempat penyimpanan yang sangat jarang, bahkan tidak pernah keluar dari tempat penyimpanan dalam jangka waktu lama. Jadi arsip inaktif ini hanya kadang-kadang saja diperlukan dalam proses penyelenggaraan kegiatan. Arsip inaktif setelah jangka waktu penyimpanan habis (nilai gunanya habis) segera diproses untuk disusutkan. Didalam penyusutan arsip ditentukan mana arsip yang segera dihapus dan mana arsip yang harus disimpan terus.

Prosedur atau pengelolaan arsip pada suatu kantor berbeda satu dengan yang lainnya. Namun demikian 
tidak tertutup kemungkinan terjadi kesamaan prosedur. Pada intinya semua prosedur bertujuan agar kegiatan kearsipan dapat berjalan secara teratur, efektif dan efisien. Namun sering terjadi permasalahan jika suatu organisasi tidak melaksanakan prosedur penataan arsip secara benar. Terkadang kurangnya ketelitian petugas arsip dalam menyimpan arsip mengakibatkan kesulitan dalam penemuan kembali arsip yang sudah lama disimpan. Dengan demikian prosedur penataan arsip harus lebih diperhatikan oleh organisasi untuk menunjang efektivitas administrasi perkantoran.

Tujuan pengelolaan arsip dinamis inaktif adalah menempatkan arsip dalam sistem kearsipan yang bisa ditemukan kemudian bila dibutuhkan.

\section{MASALAH PENELITIAN}

Berdasarkan latar belakang yang telah diuraikan, Penelitian ini pada pengumpulan datanya menggunakan teknik wawancara, dokumentasi, dan observasi. Dalam hal tersebut bagaimana dan upaya apa yang dilakukan Unit Kearsipan Instansi Stasiun Karantina Ikan, Pengendalian Mutu dan Keamanan Hasil Perikanan Pontianak dalam membenahi dan mengembangkan pengelolaan arsip dinamis inaktif baik dari segi sarana maupun prasarana.

\section{TINJAUAN LITERATUR}

\subsection{Unit Kearsipan}

Adalah satuan kerja yang mempunyai tugas dan tanggung jawab mengelola arsip yang sudah diselesaikan oleh unit pengolah / unit kerja untuk disimpan, dipelihara dan digunakan. Dalam pekerjaan kantor maupun lembaga kearsipan merupakan bagian yang sangat penting, yaitu menjadi sumber informasi, sebagai pusat kegiatan suatu kantor, dan sebagai ingatan kantor, sehingga perlu suatu sistem penyimpanan yang baik dan benar tetapi mudah ditemukan kembali pada saat dibutuhkan. Hal tersebut diungkapkan Sugiarto (2005: 51) sistem penyimpanan adalah sistem yang digunakan untuk menyimpan dokumen yang sudah disimpan dengan menciptakan dan menemukan dokumen dengan cepat ketika dokumen diperlukan sewaktu-waktu. Untuk mempermudah dalam menemukan kembali arsip jika diperlukan sewaktu-waktu maka diperlukan sistem penyimpanan arsip yang tepat dan sesuai dengan kebutuhan instansi atau organisasi.

\subsection{Fungsi Unit Kearsipan}

Unit kearsipan pada pencipta arsip sebagaimana dimaksud dalam Undang-Undang Nomor 43 Tahun 2009 Pasal 17 ayat (1) tentang kearsipan memiliki fungsi:

a. Pengelolaan arsip inaktif dari unit pengolah di lingkungannya;

b. Pengolahan arsip dan penyajian arsip menjadi informasi;

c. Pemusnahan arsip di lingkungan lembaganya;

d. Penyerahan arsip statis oleh pimpinan pencipta arsip kepada lembaga kearsipan

\subsection{Aspek pengelolaan arsip dinamis inaktif}

Secara umum aspek arsip dinamis tidak lepas kaitannya dengan siklus hidup arsip yaitu tahap penciptaan dan penerimaan (creation) tahap distribusi (distribution), tahap penggunaan (use), tahap pemeliharaan (maintenance) dan disposisi akhir (disposition).

\section{METODE}

Penelitian ini menggunakan pendekatan kualitatif yaitu dengan metode studi kasus yang bertujuan untuk mengkaji permasalahan pengelolaan arsip yang ada dilingkungan Stasiun Karantina Ikan, Pengendalian Mutu dan Keamanan Hasil Perikanan Pontianak meliputi Fasilitas kearsipan, pengumpulan data dan SDM kearsipan. Penggunaan pendekatan kualitatif ini dimaksudkan agar lebih peka dan lebih dapat menyesuaikan diri dengan banyak penjelasan pengaruh bersama dan terhadap pola-pola nilai yang dihadapi peneliti.

Alasan penelitian ini menggunakan pendekatan kualitatif karena permasalahan pengelolaan arsip inaktif dalam upaya mendukung layanan informasi di Instansi Stasiun Karantina Ikan, Pengendalian Mutu dan Keamanan Hasil Perikanan Pontianak, berkenaan dengan angka-angka pemakaian atau penerbitan sertifikat kesehatan karantina ikan dan mutu, tetapi mendeskripsikan secara jelas dan terperinci serta peroleh data yang mendalam dari fokus penelitian. Hasil dari penelitian kualitatif selalu berusaha mengungkap suatu masalah, keadaan atau peristiwa yang sebenarnya sebagaimana mestinya. Data yang diperoleh dari seluruh personil dan pihak yang berkepentingan dengan data dilingkup Stasiun Karantina Ikan Pengendalian Mutu dan Keamanan Hasil Perikanan Pontianak.

\section{INFORMAN PENELITIAN}

Berdasarkan dengan dasar dari penelitian ini, yaitu studi kasus. Pengelolaan arsip dan 
dokumentasi yang mengurusi secara langsung pengelolaan arsip inaktif tersebut, antara lain :

a. Orang yang ahli dalam bidang kearsipan;

b. Orang yang terlibat dalam bidang kearsipan, misalnya arsiparis;

c. Orang yang berkepentingan dalam bidang kearsipan, misalnya peminjam arsip.

\section{TEKNIK PENGUMPULAN DATA}

Beberapa teknik pengumpulan data yang dilakukan sebagai berikut:

\section{a. Wawancara}

Wawancara adalah percakapan dengan maksud tertentu. Percakapan itu dilakukan oleh dua pihak, yaitu pewawancara (interviewer) yaitu pengolah arsip yang mengajukan pertanyaan dan terwawancara (interviewee) yaitu Unit Pengolah (dari masing-masing bidang) yang memberikan jawaban atas pertanyaan itu" (lexy j moleong, 2007: 186). Wawancara dilakukan oleh peneliti terhadap para informan dalam bentuk tanya jawab dengan menggunakan pedoman wawancara. Teknik wawancara dalam penelitian ini berupa interview terhadap informan. Wawancara ini dilakukan untuk mencari data-data yang ada mengenai pengelolaan arsip inaktif dalam upaya mendukung layanan informasi di Instansi Stasiun Karantina Ikan Pengendalian Mutu dan Keamanan Hasil Perikanan Pontianak. Alat yang digunakan untuk wawancara ini meliputi alat perekam, kertas, kamera dan alat pendukung lainnya. Adapun wawancara yang dilakukan peneliti di masing-masing Unit pengolah antara lain:

1. Unit Pengolah di Bidang Tata Pelayanan

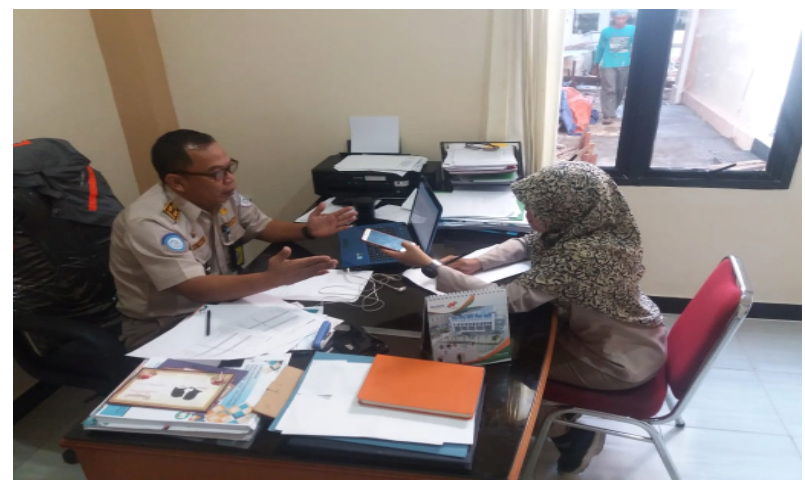

Gambar 1

\section{Unit Pengolah di Bidang Tata Usaha}

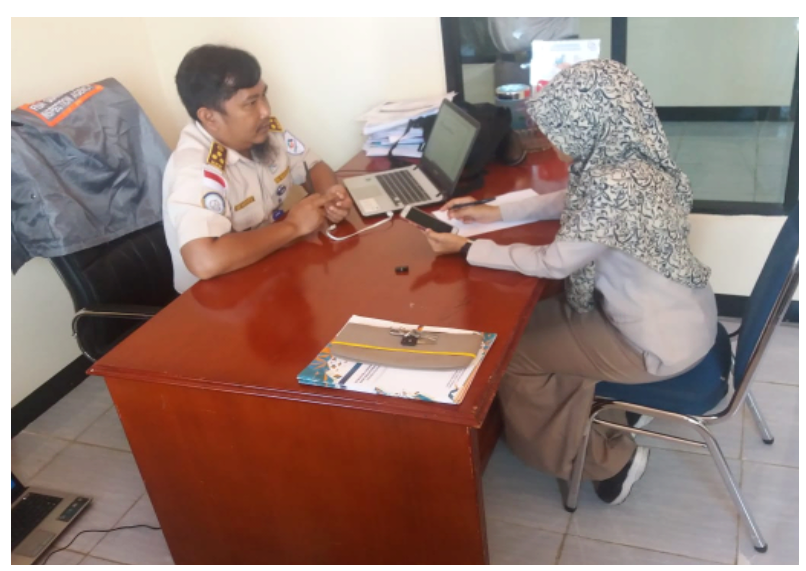

Gambar 2

3. Unit Pengolah di Bidang Pengawasan Pengendalian dan Informasi (P2I)



Gambar 3

\section{b. Observasi}

Menurut sugiyono (2010:203), "metode observasi sebagai tehnik pengumpulan data mempunyai ciri yang spesifik bila dibandingkan dengan teknik yang lain, yaitu wawancara dan kuesioner". Observasi yang digunakan dalam penelitian ini dilakukan secara terbuka yaitu observasi yang menempatkan fungsi pengamat secara terbuka diketahui oleh subjek dan subjek memberikan kesempatan kepada pengamat untuk mengamati peristiwa yang terjadi. Hal-hal yang diobservasi dalam penelitian ini adalah situasi dan kondisi masing-masing subbagian yang menyimpan arsip dalam pengelolaan arsip. Adapun hasil observasi yang dilakukan peneliti dilingkup Stasiun Karantina Ikan Pengendalian Mutu dan Keamanan Hasil Perikanan Pontianak bahwa fasilitas yang telah digunakan dalam pengelolaan arsip dinamis inaktif sebagai berikut: 
Tabel 1. Fasilitas Pengelolaan Arsip Dinamis Inaktif pada Unit Kearsipan lingkup Stasiun Karantina Ikan, Pengendalian Mutu dan Keamanan Hasil Perikanan Pontianak

\begin{tabular}{|c|c|c|c|}
\hline No & Fasilitas Kearsipan & Jumlah & Kondisi \\
\hline 1 & $\begin{array}{c}\text { Ruang penyimpanan/ Record } \\
\text { Center }\end{array}$ & 1 & Baik \\
\hline 2 & Lemari Arsip & 4 & Baik \\
\hline 3 & Rak Arsip & 10 & Baik \\
\hline 4 & Boks Arsip & 262 & Baik \\
\hline 5 & Meja Kerja & 1 & Baik \\
\hline 6 & Kursi Kerja & 1 & Baik \\
\hline 7 & Komputer & 1 & Baik \\
\hline 8 & Printer & 1 & Baik \\
\hline
\end{tabular}

Tabel 2. Fasilitas Pengelolaan Arsip Dinamis Inaktif pada Unit Pengolah Kepala Urusan Tata Usaha

\begin{tabular}{|c|c|c|c|}
\hline No & Fasilitas Kearsipan & Jumlah & Kondisi \\
\hline 1 & Ruang penyimpanan & 1 & Baik \\
\hline 2 & Lemari Arsip & 1 & Baik \\
\hline 3 & Boks Arsip & 10 & Baik \\
\hline 4 & Meja Kerja & 1 & Baik \\
\hline 5 & Kursi Kerja & 1 & Baik \\
\hline 6 & Komputer & 1 & Baik \\
\hline 7 & Printer & 1 & Baik \\
\hline
\end{tabular}

Tabel 3. Fasilitas Pengelolaan Arsip Dinamis Inaktif pada Unit Pengolah Kasubsie Tata Pelayanan

\begin{tabular}{|c|c|c|c|}
\hline No & Fasilitas Kearsipan & Jumlah & Kondisi \\
\hline 1 & Ruang penyimpanan & 1 & Baik \\
\hline 2 & Lemari Arsip & 1 & Baik \\
\hline 3 & Rak Arsip & 2 & Baik \\
\hline 4 & Boks Arsip & 180 & Baik \\
\hline 5 & Meja Kerja & 1 & Baik \\
\hline 6 & Kursi Kerja & 1 & Baik \\
\hline 7 & Komputer & 1 & Baik \\
\hline 8 & Printer & 1 & Baik \\
\hline
\end{tabular}

Tabel 4. Fasilitas Pengelolaan Arsip Dinamis Inaktif pada Unit Pengolah Kasubsie Pengawasan Pengendalian dan Informasi

\begin{tabular}{|c|c|c|c|}
\hline No & Fasilitas Kearsipan & \multirow{2}{*}{ Jumlah } & Kondisi \\
\hline 1 & Ruang penyimpanan & 1 & Baik \\
\hline 2 & Lemari Arsip & 1 & Baik \\
\hline 3 & Boks Arsip & 10 & Baik \\
\hline 4 & Meja Kerja & 1 & Baik \\
\hline 5 & Kursi Kerja & 1 & Baik \\
\hline 6 & Komputer & 1 & Baik \\
\hline 7 & Printer & 1 & Baik \\
\hline
\end{tabular}




\section{c. Dokumentasi}

Dokumentasi sebagai penunjang data hasil wawancara dan observasi, digunakan untuk memperoleh data atau informasi, misalnya mengenai jumlah atau frekuensi pemakaian sertifikat kesehatan karantina ikan lingkup Stasiun Karantina Ikan, Pengendalian Mutu dan Keamanan Hasil Perikanan
Pontianak. Teknik dokumentasi dalam penelitian ini dilakukan dengan cara mengambil data dan gambar/ foto maupun grafik tentang kegiatan yang berhubungan dengan pengelolaan arsip.

1. Frekuensi Pemakaian Sertifikat Kesehatan Ikan Tahun 2016 sampai dengan Tahun 2018 (tabel dan grafik)

Tabel 5. Frekuensi Pemakaian Sertifikat Kesehatan Ikan Tahun 2016 sampai dengan Tahun 2018 Lingkup Stasiun Karantina Ikan Pengendalian Mutu dan Keamanan Hasil Perikanan Pontianak

\begin{tabular}{|c|l|c|c|c|}
\hline \multirow{2}{*}{ No Uraian } & \multicolumn{3}{|c|}{ Jumlah Pemakaian Sertifikat } \\
\cline { 3 - 5 } & & 2016 & 2017 & 2018 \\
\hline 1 & Sertifikat Pelepasan Domestik Masuk (KI-D12) & 1396 & 1360 & 1174 \\
\hline 2 & Sertifikat Pelepasan SKLL (KI-D7) & 328 & & 126 \\
\hline 3 & Sertifikat Ekspor (KI-D1) & 364 & 367 & 747 \\
\hline 4 & Sertifikat Kesehatan Domestik Keluar (KI-D2) & 3367 & 3002 & 6162 \\
\hline 5 & Sertifikat Kesehatan Domestik Keluar SKLL (KI-D3) & & 4362 & 7368 \\
\hline
\end{tabular}

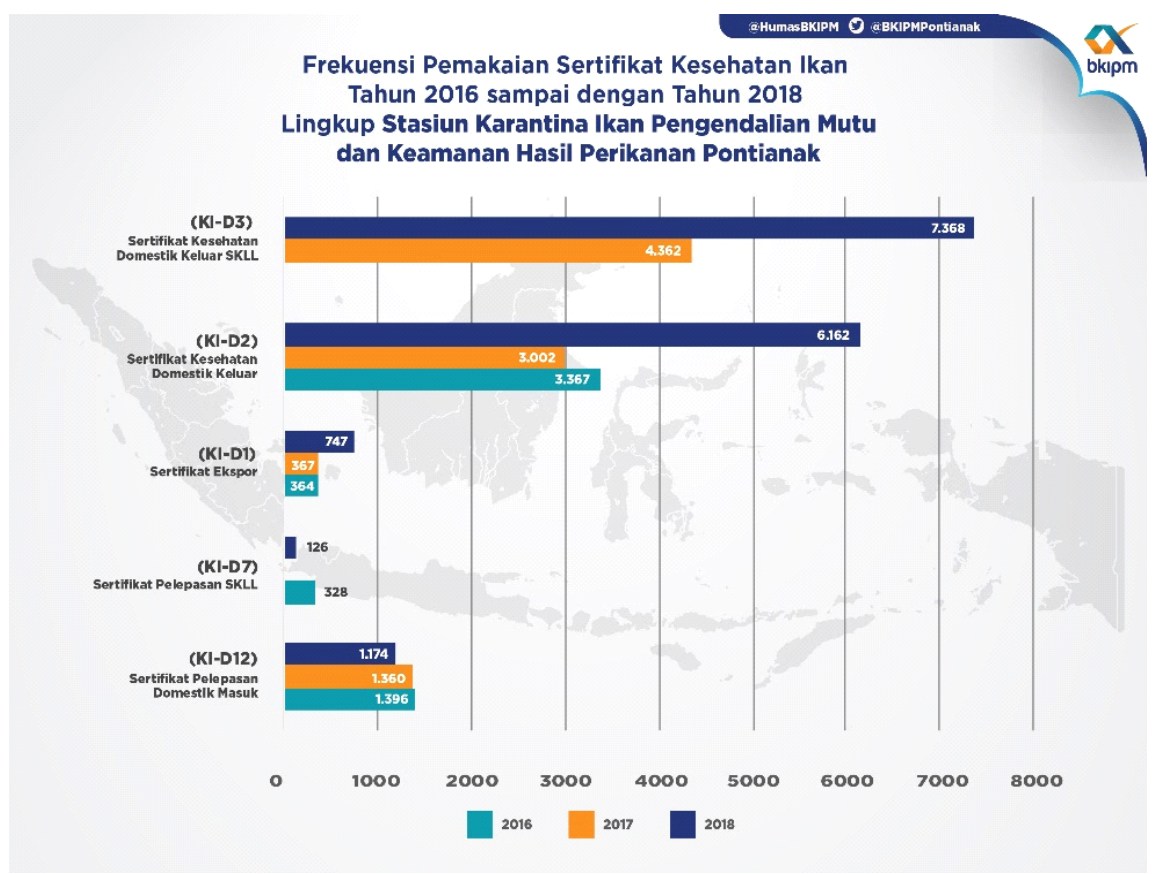

Grafik 1. Frekuensi Pemakaian Sertifikat Kesehatan Ikan Tahun 2016 sampai dengan Tahun 2018 Lingkup Stasiun Karantina Ikan Pengendalian Mutu dan Keamanan Hasil Perikanan Pontianak 
2. Fasilitas Kearsipan dilingkup Stasiun Karantina Ikan, Pengendalian Mutu dan Keamanan Hasil Perikanan Pontianak (gambar)

a. $\mathrm{G} \epsilon$

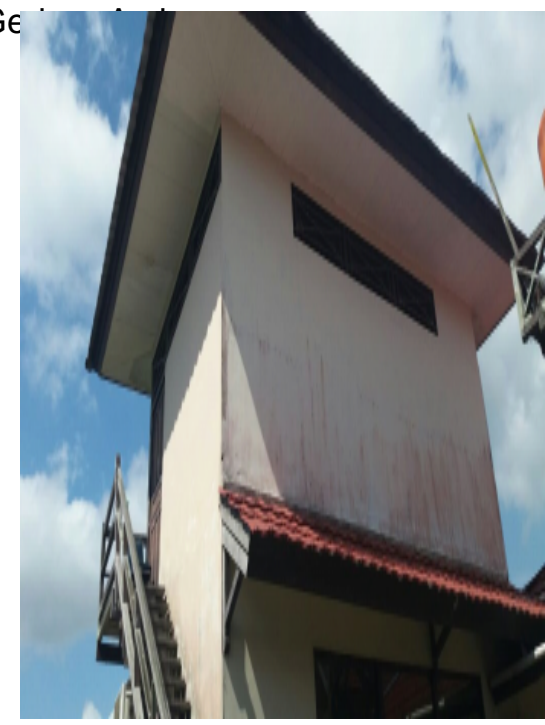

Gambar 4. Gedung arsip lama



Gambar 4. Gedung arsip baru b. Rak Arsip

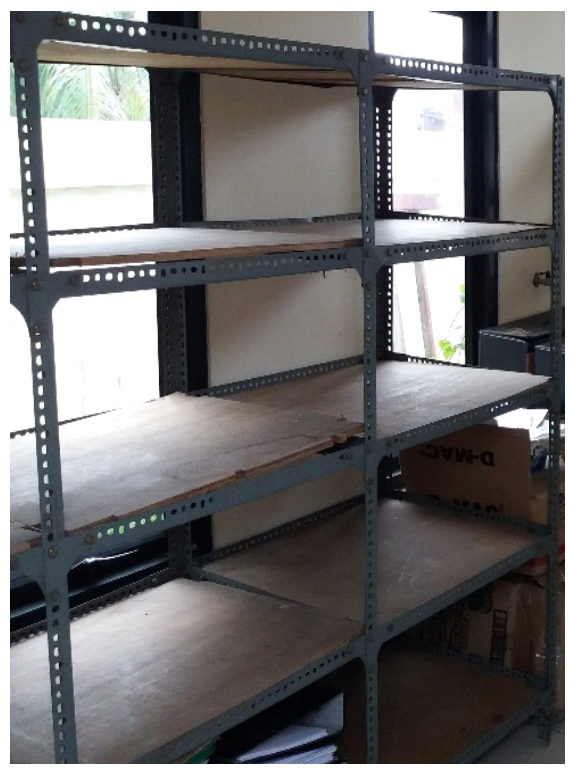

Gambar 6. Rak Arsip Lama

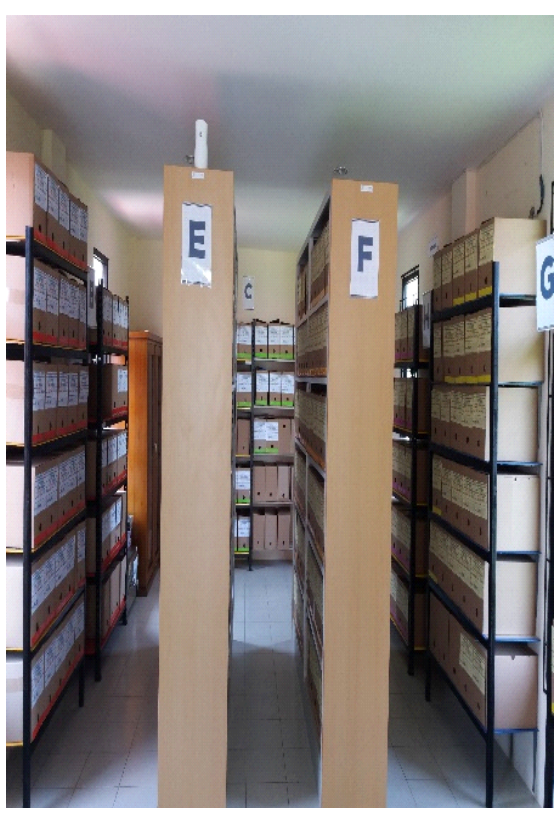

Gambar 6. Rak Arsip Baru 
c. Boks Arsip

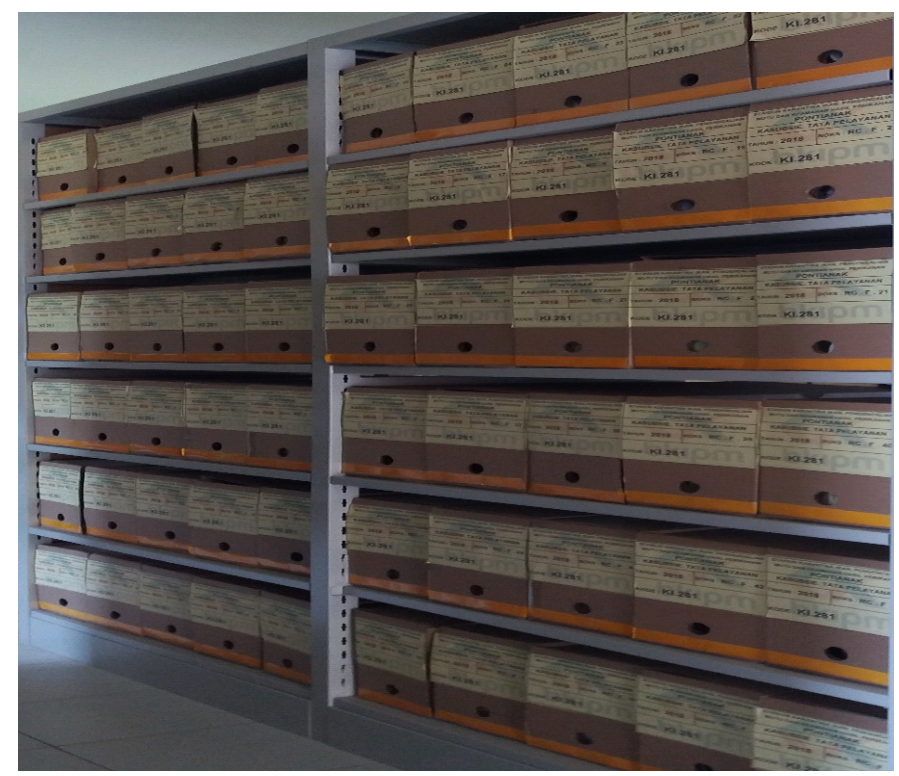

Gambar 8

3. Kegiatan Penyusutan arsip dari Tahun 1996 sampai dengan Tahun 2014 (table dan grafik)

Tabel 6. Kegiatan Penyusutan Arsip dari Tahun 1996 sampai dengan Tahun 2014 di Lingkup Stasiun Karantina Ikan Pengendalian Mutu dan Keamanan Hasil Perikanan Pontianak

\begin{tabular}{|c|c|c|c|c|c|c|}
\hline \multirow{3}{*}{ No } & \multirow{3}{*}{ Uraian } & \multirow{2}{*}{\multicolumn{2}{|c|}{$\begin{array}{c}\text { Jumlah Arsip Yang } \\
\text { Disusutkan } \\
\text { UPT (nomor) }\end{array}$}} & \multirow{2}{*}{\multicolumn{3}{|c|}{$\frac{\text { Jumlah Arsip Yang Disusutkan }}{\text { Wilayah Kerja (nomor) }}$}} \\
\hline & & & & & & \\
\hline & & $1996-2012$ & 2013 & $2006-2012$ & 2013 & 2014 \\
\hline 1 & Sertifikat Ekspor & 2.532 & 279 & - & - & - \\
\hline 2 & Sertifikat Kesehatan & 40.658 & 6.541 & 11.594 & 611 & 1.223 \\
\hline 3 & Sertifikat Pelepasan & 3.840 & 4.536 & 552 & 111 & 111 \\
\hline 4 & SKLL & - & - & - & - & 4.124 \\
\hline 5 & Umum & 1.614 & - & - & 1.090 & 2.453 \\
\hline
\end{tabular}

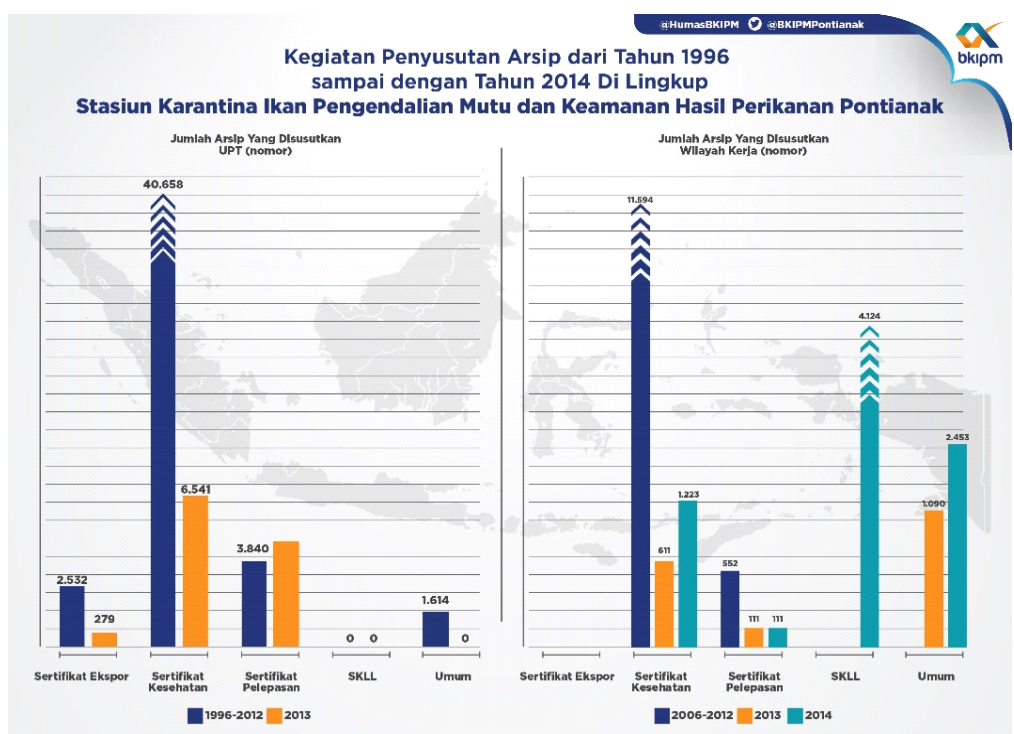

Grafik 2. Grafik Kegiatan Penyusutan Arsip dari Tahun 1996 sampai dengan Tahun 2014 Di Lingkup Stasiun Karantina Ikan Pengendalian Mutu dan Keamanan Hasil Perikanan Pontianak 


\section{HASIL DAN PEMBAHASAN}

Berdasarkan hasil dari penelitian dilingkup Stasiun Karantina Ikan Pengendalian Mutu dan Keamanan Hasil Perikanan Pontianak adalah sebagai berikut:

1. Peningkatan penyelenggaraan sistem kearsipan melalui peningkatan kualitas sumber daya manusia;

2. Meningkatnya sarana dan prasarana untuk mendukung pengelolaan kearsipan;

3. Peningkatan layanan kearsipan.

Instansi Stasiun Karantina Ikan, Pengendalian Mutu dan Keamanan Hasil Perikanan Pontianak salah satu Unit Pelaksana Teknis Badan Karantina Ikan, Pengendalian Mutu dan Keamanan Hasil Perikanan Kementerian Kelautan dan Perikanan sebagai sarana pembangunan untuk meningkatkan sumber daya manusia dalam kearsipan. Instansi Stasiun Karantina Ikan, Pengendalian Mutu dan Keamanan Hasil Perikanan Pontianak secara garis besarnya bertugas untuk menangani arsip baik Arsip Substantif maupun Arsip Pasilitatif. Instansi Stasiun Karantina Ikan, Pengendalian Mutu dan Keamanan Hasil Perikanan Pontianak adalah instansi yang dipimpin olek Kepala Stasiun Karantina Ikan, Pengendalian Mutu dan Keamanan Hasil Perikanan Pontianak dan bertanggung jawab kepada Badan Karantina Ikan, Pengendalian Mutu dan Keamanan Hasil Perikanan. Instansi tersebut memiliki 3 (tiga) struktural dibawahnya yaitu Kepala Urusan Tata Usaha, Kasubsie Tata Pelayanan dan Kasubsie Pengendalian Pengawasan dan Informasi (P2I).

\section{Pencatatan Arsip}

Pencatatan arsip yang ada di lingkungan Stasiun Karantina Ikan, Pengendalian Mutu dan Keamanan Hasil Perikanan Pontianak meliputi, penerimaan, penyortiran, registrasi, pendistribusian, pola klasifikasi arsip dan penataan arsip. Pencatatan arsip dilakukan karena arsip sewaktu-waktu pasti dibutuhkan. Apabila arsip tersebut tidak dicatat dan didata dengan baik dan benar maka saat arsip tersebut dibutuhkan kembalibsulit dicari dan yang akhirnya dalam pemenuhan kebutuhan informasi bagi yang membutuhkan akan terhambat.

\section{Penyimpanan Arsip}

Sistem penyimpanan arsip yang digunakan di lingkungan Stasiun Karantina Ikan, Pengendalian Mutu dan Keamanan Hasil Perikanan Pontianak dengan sistem kodefikasi yang disimpan di Record Center Stasiun Karantina Ikan, Pengendalian Mutu dan Keamanan Hasil Perikanan Pontianak. Hal tersebut sesuai dengan Amsyah, (2005:71) "Sistem Penyimpanan adalah sistem yang dipergunakan pada penyimpanan warkat agar kemudahan kerja penyimpanan dapat diciptakan dan penemuan warkat yang sudah disimpan dapat dilakukan dengan cepat bilamana warkat tersebut sewaktu-waktu diperlukan.

\section{Pengawasan Arsip}

Stasiun Karantina Ikan, Pengendalian Mutu dan Keamanan Hasil Perikanan Pontianak dalam setiap masing-masing subbagian harus memiliki tanggung jawab dalam hal penyelamatan atau pengamanan arsipnya masing-masing, tetapi penanggung jawab semuanya terpusatkan pada Kepala Stasiun Karantina Ikan, Pengendalian Mutu dan Keamanan Hasil Perikanan Pontianak. Ruang penyimpanan arsip yang digunakan untuk menyimpan arsip harus memperhatikan beberapa ketentuan supaya arsip yang disimpan dapat terjaga dengan aman.

\section{Pemindahan dan Pemusnahan Arsip}

Penyusutan atau pemusnahan arsip di Stasiun Karantina Ikan, Pengendalian Mutu dan Keamanan Hasil Perikanan Pontianak dilakukan dengan cara khusus yaitu dengan cara dibakar yang sesuai peraturan Menteri Kelautan dan Perikanan Republik Indonesia Nomor 67/PERMEN-KP/2016 tentang Kearsipan Pasal 17 ayat (3) huruf a dan b. Pemindahan arsip aktif ke inaktif dari masing masing unit pengolah secara rutin ditahun berikutnya.

\section{KESIMPULAN}

Kesimpulan yang diperoleh dari penelitian diantaranya adalah sebagai berikut:

Fasilitas Kearsipan berupa kurangnya jumlah rak disebabkan karena pemusnahan belum dilaksanakan, fire alarm system dan alat pemadam kebakaran yang belum memadai karena kurangnya ketelitian petugas dalam pengecekan pemakaian alat pemadam kebakaran.

Sistem penyimpanan arsip menggunakan sistem pokok soal, hal tersebut sudah baik karena sesuai dengan karakteristik arsip yang disimpan.

Sistem penyimpanan arsip haruslah sesuai dengan teori yang ada yaitu sistem penyimpanan arsip berdasarkan subjek agar Pengolah arsip Stasiun Karantina Ikan, Pengendalian Mutu dan Keamanan Hasil Perikanan Pontianak dapat dengan mudah melakukan pencarian informasi yang dibutuhkan 
Pengawasan arsip masing-masing unit pengolah atau subbagian memiliki tanggung jawab untuk menyelamatkan ataupun mengamankan arsipnya sendiri. Akan tetapi yang bertanggung jawab penuh tetap Kepala Tata Usaha.

Pemusnahan arsip ini berdasarkan jadwal retensi arsip dan berdasarkan nilai guna arsip. Arsip yang dimusnahkan tersebut dinilai terlebih dahulu atau diseleksi apakah arsip itu masih layak dipakai atau sudah tidak punya nilai guna lagi dan dilakukan setiap tahun secara rutin dengan mengacu kepada jadwal retensi arsip.

\section{SARAN}

Dari kesimpulan di atas penelitian tersebut bisa menjadi masukan bagi para pembuat kebijakan dilingkungan Stasiun Karantina Ikan, Pengendalian Mutu dan Keamanan Hasil Perikanan dalam pengelolaan anggaran dibidang kearsipan dan dapat dijadikan referensi penulisan selanjutnya dalam topik yang sama serta dapat menampilkan data-data yang lebih lengkap lagi sehingga penelitian ini lebih baik, diperlukan tenaga outsourcing terkait kearsipan sehingga dalam pengelolaan kearsipan seperti pemindahan dan pemusnahan arsip di Instansi Stasiun Karantina Ikan, Pengendalian Mutu dan Keamanan Hasil Perikanan Pontianak sehingga dapat terkelola dengan baik dan dapat memberikan dukungan dan motivasi terhadap sistem kearsipan dilingkungan Stasiun Karantina Ikan, Pengendalian Mutu dan Keamanan Hasil Perikanan sehingga pemahaman dan kesadaran dapat lebih baik dan sesuai standar kearsipan.

\section{UCAPAN TERIMA KASIH}

Ucapan terimakasih penulis sampaikan kepada Pimpinan di Kepala Stasiun Karantina Ikan, Pengendalian Mutu dan Keamanan Hasil Perikanan Pontianak beserta pejabat struktural dibawahnya yakni Kepala Urusan Tata Usaha, Kasubsie Tata Pelayanan dan Kasubsie Pengawasan Pengendalian dan Informasi serta Pimpinan Pembina Kearsipan di Lingkungan Kementerian Kelautan dan Perikanan yakni Biro Umum, serta teman-teman yang sudah banyak membantu memberikan data-data penyusunan penulisan jurnal ini sehingga dapat merangkai jurnal ini dengan maksimal.

\section{DAFTAR PUSTAKA}

- Peraturan Perundang-undangan

Undang-Undang Nomor 43 Tahun 2009 tentang Kearsipan

Undang-Undang Nomor 43 Tahun 2009 tentang Kearsipan Pasal 17 ayat (1)

Peraturan Menteri Kelautan dan Perikanan Republik Indonesia Nomor 67/PERMEN-KP/2016 tentang Kearsipan di Lingkungan Kementerian Kelautan dan Perikanan Pasal 17 ayat (3) point a dan b

- Buku dan Makalah

Amsyah, Zulkifli. 2003. Manajemen Kearsipan. Jakarta : Gramedia Pustaka Utama.

Zulkarnain, W. \& Sumarsono, R. B. 2015. Manajemen Perkantoran Profesional. Malang: Gunung Samudra.

Sugiarto, A.W. T. 2005. Manajemen Kearsipan Modern dari Konvensional ke Basis Komputer. Yogyakarta: Gava Media.

Moleong, J.Lexy. 2013. Metode Penelitian Kualitatif. Bandung: PT Remaja Rosdakarya Offset.

Sugiyono. 2010. Metode Penelitian Pendidikan Pendekatan Kuantitatif, Kualitatif, dan R\&D. Bandung: Alfabeta.

Amsyah, Zulkifli. 2005. Manajemen Kearsipan. Jakarta: PT Gramedia Pustaka Utama. 